\title{
Obstructive airway disease associated with occupational sodium hydroxide inhalation
}

\author{
Amihai E Rubin, Lea Bentur, Yedidia Bentur
}

\begin{abstract}
Sodium hydroxide (NaOH) is well known for its corrosive properties and its ability to generate heat on contact with water. The respiratory effects of industrial exposure to $\mathrm{NaOH}$ have, however, never been reported. $\mathrm{A}$ 63 year old man worked daily for 20 years cleaning large industrial jam containers by boiling lye (NaOH) solution without using respiratory protective equipment. Physical examination, chest $x$ ray film, pulmonary function tests, and arterial blood gases were all compatible with severe obstructive airway disease with significant air trapping. It is probable that this massive and prolonged occupational exposure to the corrosive effect of $\mathrm{NaOH}$ mists induced irritation and burns to the respiratory system, eventually leading to severe obstructive airway disease.
\end{abstract}

Sodium hydroxide $(\mathrm{NaOH})$ is a white odourless, non-volatile, deliquescent, alkaline material marketed in solid form as pellets, flakes, lumps, or sticks. It is soluble in water and is commonly available as an aqueous solution known as lye. ${ }^{1}$ It has various uses, including acid neutralisation; in petroleum refining, in manufacture of paper, cellulose, textiles, plastics, explosives, dyestuffs, paint, paint remover, and soap; and in electroplating, metal cleaning, laundering, bleaching, and dish washing. The substance is highly corrosive and contact with water or moisture may generate large amounts of heat. The ceiling exposure limit is $2 \mathrm{mg} / \mathrm{m}^{3} .^{2}$ It causes irritation and severe penetrating burns of the skin, eyes, and mucous membranes by inducing liquefaction necrosis, saponification of fats, and solubilisation of proteins. ${ }^{3}$ The severity of the lesions depends on concentration and duration of exposure. Adequate engineering control, impervious gloves, boots, goggles, and other

Division of Pulmonary Diseases and Israel Poison Information Center

Y Bentur

Rambam Medical Center, Faculty of Medicine, Technion, Haifa, Israel

A E Rubin, L Bentur clothing are therefore essential, as well as the use of respirators with dust and mist filters.

The effects of occupational exposure to $\mathrm{NaOH}$ by inhalation have never been described. Here we report a patient in whom prolonged and massive inhalation of $\mathrm{NaOH}$ mists in the workplace apparently resulted in severe obstructive airway disease. Possible mechanisms are discussed.

\section{Case report}

A 63 year old man worked between 1966 and 1986 cleaning large containers used for cooking jam. The procedure included bringing concentrated lye from a storage area, mixing two buckets of this (15 l each) with 1001 water in each jam container, boiling the solution for two hours, and then draining and rinsing the containers thoroughly. The work took place in a room roughly $5 \mathrm{~m}^{2}$ in area where two uncovered containers were placed. Although a hood was installed in the ceiling it was very old and its fan and exhaust pipe often malfunctioned. Two doors and several windows that were supposed to provide some fresh air were not kept open regularly. The patient was careful to use impervious boots, gloves, and gown, but never wore any respirator or mask as these were not provided by the employer. No environmental inspections took place at that time. During the cleaning process the man always experienced tightness of chest, dyspnoea, cough, and eye irritation, which resolved after leaving the exposure area. He did not seek any medical attention until 1986 when he began suffering from a mild exertional dyspnoea and cough. He was then diagnosed, at another hospital, as having severe obstructive airway disease with moderate air trapping. Bronchodilators and inhaled and systemic corticosteroids were given and resulted in minor improvement. Later on that year he broke his right leg and was discharged from work. In 1991 he was referred to our Medical Centre with complaints of cough and dyspnoea on mild effort without orthopnoea, paroxysmal nocturnal dyspnoea, nocturia, or chest pain. The patient has never smoked, never had asthma, and his medical and family histories are unremarkable. His work before 1966 consisted only of assembling metal spring beds. His residence has been in a non-polluted small town. It is important to note that his coworkers refused to 
Pulmonary function tests

\begin{tabular}{|c|c|c|}
\hline & Observed & $\%$ Predicted \\
\hline FVC (1) & $2 \cdot 25$ & 63.8 \\
\hline FEV $_{1}$ & 0.88 & 31.7 \\
\hline FEV $_{1} /$ FVC $(\%)$ & $39 \cdot 1$ & 51.6 \\
\hline ITGV (1) & $5 \cdot 1$ & 152 \\
\hline$R V(1)$ & 4.0 & 173 \\
\hline RV/TLC (\%) & $61 \cdot 0$ & 158 \\
\hline $\mathrm{MMEF}_{25-75}(\mathbf{1} / \mathbf{s})$ & 0.32 & 9.9 \\
\hline $\operatorname{PEF}(1 / \mathrm{s})$ & 1.87 & $24 \cdot 7$ \\
\hline $\operatorname{MEF}_{50}(1 / s)$ & 0.35 & $8 \cdot 7$ \\
\hline $\mathbf{M E F}_{25}(\mathbf{l} / \mathbf{s})$ & 0.2 & $15 \cdot 1$ \\
\hline TLCo $/ \mathrm{VA}(\mathrm{mmol} / \mathrm{min} / \mathrm{kPa})$ & 1.61 & $92 \cdot 8$ \\
\hline
\end{tabular}

FVC = Forced vital capacity; FEV $_{1}=$ forced expiratory volume in one second; $R V=$ residual volume; $T L C=$ total lung capacity MMEF = maximum mid-expiratory flow; $M E F=$ maxima expiratory flow; PEF = peak expiratory flow; TLCO = carbon monoxide transfer factor; $\mathrm{VA}_{\mathbf{A}}=$ alveolar volume.

Patient's weight $71 \mathrm{~kg}$, height $165 \mathrm{~cm}$.

perform the cleaning task because of the associated dyspnoea. Physical examination showed tachypnoea $(22 / \mathrm{min})$, heart rate $104 / \mathrm{min}$ regular, blood pressure $140 / 80$, barrel chest with limited movements, and diffuse expiratory wheezing. The results of the rest of the examination were within normal limits. Chest $x$ ray film showed severe hyperinflation. An electrocardiogram was normal. Pulmonary function tests were again compatible with severe obstructive airway disease with moderate air trapping (table). These did not reverse after salbutamol inhalation. Single breath CO diffusion measurement corrected for lung volume was normal $(1.61 \mathrm{mmol} / \mathrm{min} / \mathrm{kPa}, 92.8 \%$ predicted). Arterial blood gases showed hypoxaemia with no $\mathrm{CO}_{2}$ retention, $\mathrm{PaO}_{2} 10.05 \mathrm{kPa}(75.4 \mathrm{mmHg}), \mathrm{PaCO}_{2}$ $4.48 \mathrm{kPa}(33.6 \mathrm{mmHg})$, pH 7.45 , bicarbonate concentration $23 \mathrm{mmol}(\mathrm{mEq}) / 1$, and $\mathrm{O}_{2}$ saturation $95.4 \%$ with an alveolar arterial $\mathrm{Po}_{2}$ gradient of $4.21 \mathrm{kPa}(31.6 \mathrm{~mm} \mathrm{Hg}) . \alpha_{1}$-Antitrypsin concentration was $1.67 \mathrm{~g} / 1$ (normal $2.0-4.0 \mathrm{~g} / \mathrm{l}$ ). Other haematological and biochemical parameters were normal. Sputum and skin tests for tuberculosis were negative.

\section{Discussion}

Several disorders such as asthma, chronic bronchitis, emphysema, and small airways disease may manifest as obstructive airway disease. Occupational exposures are more and more appreciated as a cause of these disorders. ${ }^{4}$ None of the common aetiologies seem to have contributed to the severe obstructive airway disease found in this patient. A borderline $\alpha_{1}$ antitrypsin concentration coupled with normal $\mathrm{CO}$ transfer capacity of the lung do not support panacinar emphysema as the main cause for the severe airway obstruction.

Although late onset asthma cannot be definitely excluded, considering the occupational setting it is probable that the prolonged, repeated, and heavy exposure to $\mathrm{NaOH}$ mists induced the obstructive airway disease.
Acute inhalation of $\mathrm{NaOH}$ mists is known to cause irritation of the nose, throat, and lung and may result in pneumonitis and pulmonary oedema. There is no evidence that acute short term exposure to $\mathrm{NaOH}$ mists will have permanent consequences. The effects of long term industrial exposure to $\mathrm{NaOH}$ mists have never been reported. This may be due to the strong and immediate irritation deterring the worker from further exposure. Dluhos $e t$ al studied the effect of biweekly, 30 minute aerosol inhalation of a $40 \%$ $\mathrm{NaOH}$ solution over a two and a half month period on the respiratory system of rats. ${ }^{5}$ They found inflammatory bronchial changes consisting of proliferated, wrinkled epithelium, sometimes flattened or ulcerated and necrotic. Peribronchial lymphoid tissue, especially near the large bronchi, was extremely thickened, penetrating the muscular layer and extruding into the bronchial lumen. Some alveoli were emphysematous. Other studies from this group did not show similar findings after exposure to aerosol $\mathrm{NaOH}$ concentrations as high as $20 \% .^{5}$ Sodium hydroxide ingestion is known to induce inflammation followed by granulation and scar formation leading to oesophageal obstruction. ${ }^{3}$

We postulated that over many years the highly corrosive nature of $\mathrm{NaOH}$ mists induced a bronchial inflammatory reaction leading to irreversible increased airway resistance. Fibrous tissue formation, similar to that found in postcaustic oesophageal lesions, might have been the reason for irreversible airway obstruction. The high water solubility and possible large droplet size of $\mathrm{NaOH}$ may have prevented significant penetration of the lower respiratory tract, thus explaining the absence of diffusion abnormality.

Although being an unusual exposure, this report further indicates the importance of using appropriate respiratory protective measures when working with $\mathrm{NaOH}$ mists.

Requests for reprints to: Yedidia Bentur MD, Israel Poison Information Center, Rambam Medical Center, Haifa 31096, Israel.

1 US Department of Health, Education and Welfare. Occupational diseases. A guide to their recognition. Cincinnati: US Department of Health, Education and Welfare. Public Health Service, Center for Disease Control, National Institute for Occupational Safety and Health, June 1977, 433-4.

2 National Institute for Occupational Safety and Health. Occupational health guidelines for chemical hazards (sodium hydroxide). Cincinnati: US Department of Health and Human Services, US Department of Labor. 1981 (DHHS (NIOSH) publ No 81-123.)

3 Ellenhorn M, Barceloux DJ. Medical toxicology. Diagnosis and treatment of human poisoning. New York: Elsevier, 1988, 929-33.

4 Dantzker DR, Pingleton SK, Pierce DA, et al. Standards for the diagnosis and care of patients with chronic obstructive pulmonary disease (COPD) and asthma. Am Rev Respir Dis monary disease

5 Dluhos M, Sklensky B, Vysckocil J. Experimental study of the effect of aerosol inhalations of a caustic soda solution on the respiratory system of rats. Vnitrni lekarstvi 1969;15:38-42. (In Czechoslovakian.)

Accepted 8 July 1991 